\title{
Micropropagation of Hardy Hibiscus (Hibiscus Moscheutos L.)
}

\author{
Elena Lobodina* , Ivan Suprun, Ekaterina Al-Nakib, Anastasia Avakimyan, and Evgeniya \\ Tyschenko
}

Federal State Budget Scientific Institution «North Caucasian Federal Scientific Center of Horticulture, Viticulture, Wine-making», 39 str. 40 Let Pobedy, Krasnodar, 350901, Russia

\begin{abstract}
Hardy hibiscus (Hibiscus x moscheutos L.) is gaining popularity as a landscape plant and the accelerated increase in the volume of planting material is of particular relevance. The work investigated the effect of the concentration of 6-BAP $(0.5,1.0,1.5 \mathrm{mg} / \mathrm{L})$ on the shoot formation of hibiscus of the following varieties: $c v$. Cranberry Crush, Fantasia, Fireball, Jazzberry Jam. It was revealed that the concentration of 6-BAP $0.5 \mathrm{mg} / \mathrm{L}$ is optimal for the proliferation of microshoots of Hibiscus $x$ moscheutos $\mathrm{L}$. With the increase in the concentration of 6-BAP, the number of formed microshoots decreases.
\end{abstract}

\section{Introduction}

The genus Hibiscus has more than 250 species, including annual and perennial herbaceous forms and ending with small woody shrubs [1]. Representatives of various species of the genus Hibiscus, due to their attractiveness, are used for landscaping for various purposes, including in coastal areas with a high salt content, and some species are used as raw materials for the preparation of medicines [2-4].

Hardy hibiscus (Hibiscus $x$ Moscheutos L.) is one of the species that is a promising crop for the landscaping objects for various purposes [5].

Hibiscus plants have beautiful flowers with a diameter of $5-30 \mathrm{~cm}$ with the bright color of petals, differ in a variety of shapes and colors of leaves, size of bushes, are characterized by a long flowering period (up to 3 months). The mature plants grow from 0.6 to $2.4 \mathrm{~m}$ in height, depending on the variety and growing conditions. Stems usually die off in the autumn, and new shoots appear in the spring $[5,6]$.

Production of Hardy hibiscus is carried out by dividing the bush, green cuttings and sowing seeds. Seed propagation is rarely used, because plants do not retain all the characteristics of the original variety, and plants of interspecific hybrids may not form seeds at all. Moreover, breeding for sterility of Hibiscus $x$ moscheutos L. is currently underway, since sterile hibiscus plants have a longer flowering period, and unsightly fruits develop and remain on the stems at the end of the flowering season, which significantly reduces the decorative value [7, 8]. Reproduction by dividing the bush and green cuttings have

\footnotetext{
* Corresponding author: alyona2255@yandex.ru
} 
difficulties in terms of the need to grow large numbers of mother plants, as well as the relatively low rooting rate of cuttings.

In this regard, clonal reproduction is the especially relevant method of reproduction of Hardy hibiscus [9]. Microcloning of valuable varieties, rootstocks, scions, unique forms from a minimum amount of starting material, in comparison with the traditional vegetative propagation method, has a number of advantages: the ability to reproduce plants all year round regardless of the season, large-scale production in small areas and the high reproduction rate [10]. This method of reproduction is relevant when preserving endangered plant species [11].

The publications on clonal micropropagation of hibiscus in vitro are extremely rare. There are some results on the reproduction of Hibiscus syriacus L. [12], Hibiscus sabdariffa L. [13], Hibiscus srosa-sinensis L. [1, 14]. However, there is no information on in vitro cultivation of Hardy hibiscus.

Therefore, the improvement of the method of clonal micropropagation of Hardy hibiscus (Hibiscus $x$ moschetous L.), in particular, the determination of the time of initiation into in vitro culture, the optimal composition of the culture medium, cultivation conditions, adaptation, etc., is of particular relevance.

\section{Materials and methods}

The studies were carried out in the conditions of the selection and biotechnological laboratory of Federal State Budget Scientific Institution «North Caucasian Federal Scientific Center of Horticulture, Viticulture, Wine-making». For the initiation into the in vitro culture we used varieties of Hardy hibiscus (Hibiscus $x$ moschetous L.) such as $c v$. Fantasia, $c v$. Fireball, $c v$. Jazzberry Jam, $c v$. Cranberry Crush, as the most promising and demanded for the agricultural landscape purposes due to its resistance to the complex of unfavorable summer stress factors (high summer temperatures, lack of air and soil moisture, dry wind phenomena, increased insolation, etc.) [14].

To optimize the technological process, in the first decade of December, 4-year-old mother plants of hibiscus from open ground were transplanted into individual containers with the soil mixture consisting of peat, soil and sand in a 1:1:1 ratio. Further, the plants with a closed root system were grown under artificial conditions at a temperature of $22-24{ }^{\circ} \mathrm{C}$, humidity $60-75 \%$, illumination $1500 \mathrm{Lx}$. This technique was used to reduce the infectious background during the selection of explants, as well as to awaken the buds earlier.

The segments of cuttings with apical and axillary buds were used as explants. For the disinfection of explants, freshly cut shoots were segmented and washed under running water for 1.5-2 hours. After that, they were washed repeatedly with distilled water. Then, under sterile conditions, the explants were processed in $70 \%$ alcohol for 1 minute, followed by washing in sterile water and disinfection in a solution of chlorine-containing tablets "OKATAB" ( $0.5 \%$ active chlorine, exposure 12 minutes). After that, explants were washed five times in sterile distilled water. With this method of processing, the outcome of sterile explants on average for the varieties was $85 \%$.

Table 1. Outcome of sterile explants of Hibiscus x moschetous L.

\begin{tabular}{|l|c|c|}
\hline \multicolumn{1}{|c|}{ Variety } & $\begin{array}{c}\text { Common } \\
\text { number of } \\
\text { explants, pcs }\end{array}$ & $\begin{array}{c}\text { Sterile explants } \\
\text { outcome, } \%\end{array}$ \\
\hline CranberryCrush & 63 & 89 \\
\hline Fantasia & 65 & 85 \\
\hline Fireball & 60 & 79 \\
\hline JazzberryJam & 70 & 87 \\
\hline
\end{tabular}


For the initiation into the in vitro culture, the culture medium according to the DKW prescription (Driver-Kunijuki, 1984) was used, containing $6 \mathrm{~g} / 1$ agar-agar, $30 \mathrm{~g} / 1$ sucrose, $0.3 \mathrm{mg} / \mathrm{1}$ 6-benzylaminopurine (6-BAP) «Sigma Aldrich». The autoclaving was carried out at $121^{\circ} \mathrm{C}$ for 20 minutes, medium $\mathrm{pH}$ 5.9. The microshoots were subcultured on the fresh culture media every 3-4 weeks.

\section{Results and discussion}

The growth of microshoots of Hardy hibiscus began in the second week of cultivation. By the end of the third week, the passage of mericlones were carried out on the fresh culture medium for the further reproduction (Figure 1).

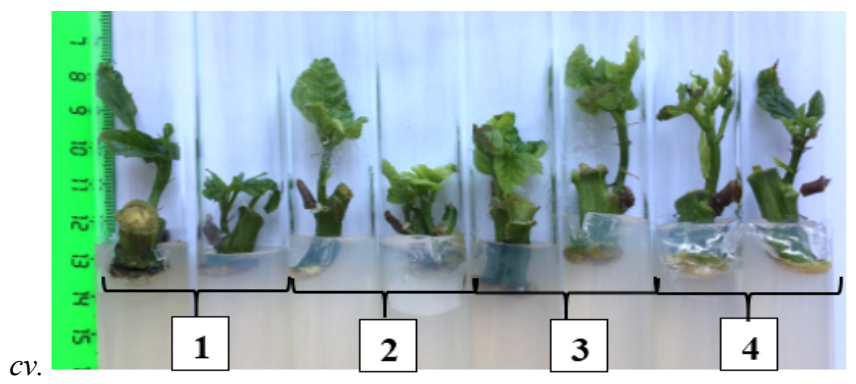

$1-c v$. Cranberry Crush; $2-c v$. Fantasia; $3-c v$. Fireball; $4-c v$. Jazzberry Jam.

Fig. 1. Hibiscus $x$ moschetous L. explants (3 weeks after introduction into culture).

At the stage of multiplication of shoots, the culture media with different contents of 6- (BAP) were tested: 0.5, 1.0, $1.5 \mathrm{mg} / \mathrm{L}$. (Table 1).

Table 2. Influence of 6-BAP Concentrations on the Multiplication of Hardy hibiscus.

\begin{tabular}{|c|c|c|c|c|}
\hline \multirow{2}{*}{\multicolumn{2}{|c|}{ Variety }} & \multicolumn{3}{|c|}{ Concentration of 6-BAP, $\mathrm{mg} / 1$} \\
\hline & & 0,5 & 1 & 1,5 \\
\hline \multicolumn{2}{|c|}{ Cr.crash } & $2,53 \pm 0,18$ & $2,17 \pm 0,31$ & $1,9 \pm 0,19$ \\
\hline \multicolumn{2}{|c|}{ Fantasia } & $3,67 \pm 0,21$ & $3,5 \pm 0,22$ & $2,67 \pm 0,21$ \\
\hline \multicolumn{2}{|c|}{ Fireball } & $2,33 \pm 0,21$ & $2,17 \pm 0,17$ & $2 \pm 0$ \\
\hline \multicolumn{2}{|c|}{ Jazzberry Jam } & $4,33 \pm 0,21$ & $3,67 \pm 0,21$ & $3 \pm 0,26$ \\
\hline \multicolumn{2}{|c|}{ Significance } & \multicolumn{3}{|c|}{$* *$} \\
\hline T-test & $5 \%$ & \multicolumn{3}{|c|}{$\begin{array}{l}0,60 \\
0,79\end{array}$} \\
\hline
\end{tabular}

According to the Table 2, it can be seen that the multiplication factor of Hardy hibiscus depends on the concentration of the hormone in the culture medium and the variety specificity in in vitro culture. The largest number of hibiscus shoots, depending on the variety, was obtained on the culture medium containing 6-BAP $0.5 \mathrm{mg} / 1$. With the increase in the concentration of 6-BAP, the number of formed microshoots were decreased.

At the stage of multiplication, the microshoots of $c v$. Fireball, $c v$. Cranberry Crush had the lowest multiplication factor, the plants were chlorotic and gradually dried out, so it was not possible to carry out the rooting stage and adaptation of microplants of these varieties. 
The grown plants were rooted after 5-6 subcultures. For the rooting microshoots of $c v$. Jazzberry Jam and $c v$. Fantasia varieties, we used DKW hormone-free culture medium. The root formation of microplants began in the second week of cultivation. The outcome of rooted plants was $100 \%$. The microplants of $c v$. Jazzberry Jam variety had more root hairs than $c v$. Fantasia (Figure 2).
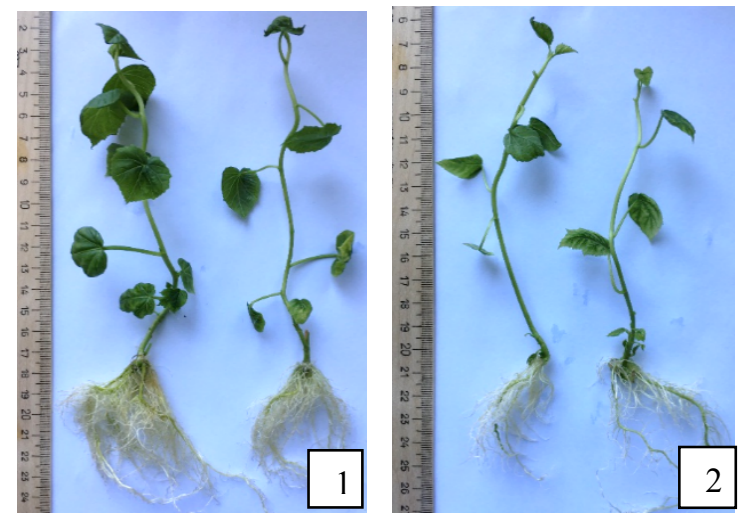

Fig. 2. Rooted hibiscus plants $c v$. Jazzberry Jam $-1, c v$. Fantasia -2 .

The rooted plants were planted in the containers with a sterile substrate consisting of garden soil, peat, vermiculite, sand in a ratio of $1: 1: 0.5: 0.5$. The planted plants were adapted under illumination of $1500 \mathrm{Lx}$, humidity $85 \%$ and temperature $24-25^{\circ} \mathrm{C}$. Conditions with high humidity were maintained until the appearance of the first new leaf for the better survival of microplants. The outcome of hibiscus plants adapted to ex vitro conditions was $83 \%$, in average for varieties (Figure 3).

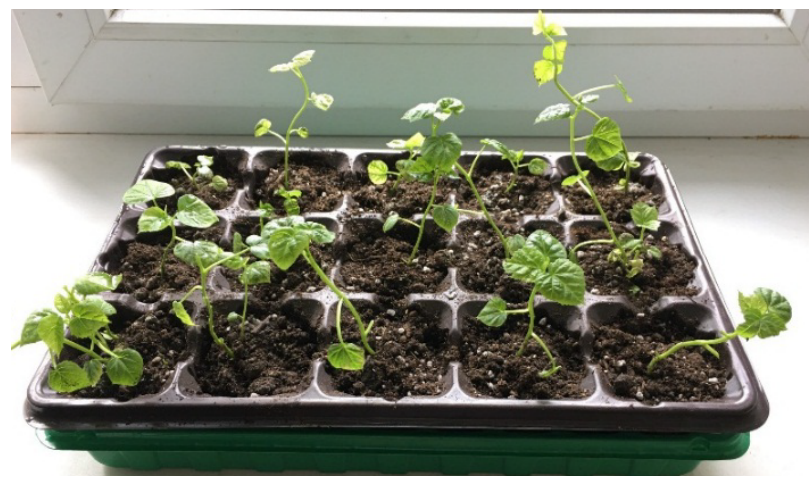

Fig. 3. Ex vitro adapted hibiscus plants $c v$. Jazzberry Jam.

\section{Conclusion}

At the stage of multiplication of microshoots of Hardy hibiscus (Hibiscus $x$ moschetous L.), the largest number of shoots was formed on the culture medium with the 6-BAP concentration of $0.5 \mathrm{mg} / 1$. With the increase in the concentration of 6-BAP, the number of formed microshoots was decreased. Hibiscus varieties such as cv. Jazzberry Jam and cv. Fantasia reproduce well in in vitro culture and have a high adaptive ability to ex vitro conditions (83\%). For the hibiscus varieties such as cv. Fireball and cv. Cranberry Crush the 
conditions of the studies were not favorable: at the stage of multiplication, they showed signs of chloroticity, drying out, which was leading to the death of microshoots.

\section{References}

1. M. Faisal, A. A. Alatar, E. M. Abdel-Salam, A. A. Qahtan, Saud. J. of Biol. Sci. 27, 412-416 (2020). https://doi.org/10.1016/j.sjbs.2019.11.002

2. S. L. Lupien, F. M. Dugan, K. M. Ward, K. O’Donnell, Plant Dis., 101, 354-358 (2017). https://doi.org/10.1094/PDIS-05-16-0717-RE

3. D. P. Malinowski, W. E. Pinchak, K. Yanker-Hansen, Front. Plant Sci, 10 (2019). https://doi.org/10.3389/fpls.2019.01528

4. H. F. Sakhanokho, N. Islam-Faridi, E. M. Babiker, C. D. Nelson, S. J. Stringer, J. J. Adamczyk, Sci.Hort., 264 (2020). https://doi.org/10.1016/j.scienta.2019.109167

5. S. L. Lupien, F. M. Dugan, K. M. Ward, and K. O’Donnell, Plant Disease, 101, 354358 (2017). https://doi.org/10.1094/PDIS-05-16-0717-RE

6. Cecil T. Pounders, Hamidou F. Sakhanokho, HortScience, 51(12), (2016). https://journals.ashs.org/hortsci/view/journals/hortsci/51/12/article-p1616.xml

7. Z. Li, J. M. Ruter, HortScience, 52(5), 676-681 (2011) https://journals.ashs.org/hortsci/view/journals/hortsci/52/5/article-p676.xml

8. D. P. Corrêa da Silva, E. A. Ozudogru, M. Valquíria dos Reis, M. Lambardi, Ornam. Hortic, 24(1) (2018) https://www.scielo.br/scielo.php?pid=S2447$\underline{36 X 2018000100028 \& \text { script }=\text { sci_arttext }}$

9. S. S. Bhojwani, P. K. Dantu (Ed.), Plant Tissue Culture: An Introductory Text (245274, 2013) https://link.springer.com/chapter/10.1007/978-81-322-1026-9_17

10. J. C. Cardoso, L. T. Sheng Gerald, J. A. Teixeira da Silva (Ed.), Micropropagation in the Twenty-First Century (V.M. Loyola-Vargas, N. Ochoa-Alejo, 17-45, 2018). https://experiments.springernature.com/articles/10.1007/978-1-4939-8594-4_2

11. A. K. Patel, D. Lodha, N. S. Shekhawat, In Vitro Cellular \& Developmental Biology Plant (2020). https://link.springer.com/article/10.1007\%2Fs11627-020-10089-6

12. S. A. Metwally, Kh. I. Hashish, S. S. Sayed, L. S. Taha, J PharmTech Research, 9(11), 178-186(2016). https://www.researchgate.net/publication/311928817

In_vitro_propagation_protocol_of_Hibiscus syriacus_L_Plants

13. S. S. Kumar, P. Manoj, P. Giridhar, In Vitro Cell.Dev.Biol, 52, 427-436 (2016). https://link.springer.com/article/10.1007/s11627-016-9785-2

14. Kh. I. Hashish, LobnaTaha, S. M. M. Ibrahim, Int.J. ChemTech Res.,8(9), 131-136 (2015).https://www.researchgate.net/publication/287251637_Micropropagation_potent iality and pigments content_of hibiscus_rosasinensis 1_As affected by gamma rad iation

15. E. L. Tyschenko, I. G. Mishchenko, Yu. P. Kashchits, Fruit growing and viticulture of South Russia 58(4), 166-179 (2019). DOI: 10.30679/2219-5335-2019-4-58-166-179 